\title{
Comparing Sorption Characteristics of Tetrabromobisphenol-A, Bisphenol-A, and 2,6-Dibromophenol in a Single-Aolute Aystem
}

\author{
Xiang Li, Xingxing Peng, Zaili Zhang, Xiaoshan Jia* \\ School of Environmental Science and Engineering, Sun Yat-Sen University, \\ Guangzhou 510275, China
}

Received: 17 November 2014

Accepted: 22 January 2016

\begin{abstract}
Tetrabromobisphenol-A (TBBPA) and its analogue compounds (bisphenol-A (BPA) and 2, 6-dibromophenol (2, 6-DBP)) sorption on CTMAB-clays was investigated in this paper through bath experiments. Montmorillonite and kaolinite modified by CTAMB, as the adsorbent, were firstly characterized by XRD, FTIR and SEManalysis. The surface areas was determined using N2 (77K) sorption-desorption analysis. Kinetic studies showed that sorption reached equilibrium in 5 hours and followed the pseudosecond order kinetic model. The intra-particle diffusion model for sorption was also investigated and compared to identify the sorption mechanism. The sorption isotherms, well fitted by Freundlich model, were changed from being non-linear to being linear with intercalating CTMAB into clays, which indicated that CTMAB increased the partition interaction. A combination of partition and specific sorption might be contributed to TBBPA and its composition products sorption mechanism. The Freundlich coefficients $(\mathrm{kF})$ and distribution coefficients $(\mathrm{kd})$ for both two adsorbents were primarily increased by increasing amount of adsorbed CTMAB, while the organic carbon normalized sorption coefficients (koc) did not follow this trend. Meanwhile, 100\%CEC-CTMAB-Montmorillonite showed an advantage of removal of the selected compounds than $100 \%$ CEC-CTAMB-Kaolinite. The sorption capacity of BPA was bigger than that of 2, 6-DBP in spite of their similar hydrophobicity, which indicated some molecule properties might influence the sorption on CTMAB-clays. Moreover, the negative $\triangle \mathrm{G} 0$ and $\triangle \mathrm{H} 0$ indicated the spontaneous and exothermal process. The TBBPA sorption on CTMAB-clays was considerably enhanced in the acid condition.
\end{abstract}

Keywords: sorption, Tetrabromobisphenol A, CTMAB, Modified clays

*e-mail: eesjxs@126.com 


\section{Introduction}

Tetrabromobisphenol-A (TBBPA) and its analogue compounds (e.g., bisphenol-A (BPA) and 2,6-dibromophenol (2,6-DBP) ) have caused significant concern due to their accumulation in the environment [1-3]. The release of these compounds into the environment occurs through manufacturing, recycling, and disposal of various materials [4-8]. They are suspected of causing a variety of adverse effects on people, including hepatoxicity, neurotoxicity, and the potential to disrupt estrogen signaling [4, 9-14]. Although the ultimate impact of these contaminants on population health remains a field of intense study, their removal from water effluents and aquatic systems is without doubt an important goal for worldwide researchers and government agencies.

Various methods have been proposed for the use and treatment of waters and wastewaters containing TBBPA and its analogue compounds [15-19]. The approach reported in this study is sorption process by clay mineral materials, which has some advantages over the other techniques, including their relatively low operational cost, ease of operation, and production of fewer byproducts.

Clay minerals belong to the family of phyllosilicate, or the sheet silicate family of minerals, which are distinguished by layered structures composed of polymeric sheets of $\mathrm{SiO}_{4}$ tetrahedra linked to sheets of $(\mathrm{Al}, \mathrm{Mg}, \mathrm{Fe})(\mathrm{O}, \mathrm{OH})_{6}$ octahedra. The electrical charge possessed by the clay minerals along with the porosity at micro level, surface functional groups, and the exchangeable cations present in the crystal structure make it a viable natural adsorbent for several pollutants in the treatment of contaminated waters. However, the materials are shown to have insignificant sorption capacity and selectivity toward several organic pollutants, along with anionic impurities. But modifications of clay minerals with suitable organic molecules enable it to be suitable for the attenuation of several organic/inorganic impurities. The organic modified clay was usually synthesized by introducing cationic surfactant molecules into the interlamellar space of clays through ion exchange, changing the surface properties of the natural clay from hydrophilic to hydrophobic, which results in a significant increase of hydrophobic organic contaminant sorption onto clays. The most common cationic surfactants used for clay modification are quaternary ammonium salts such as cetyltrimethylammonium bromide (CTMAB). Previous studies proved that clay minerals modified with CTMAB had a high affinity toward most hydrophobic organic compounds and had been utilized to remove hydrophobic organic compounds from water [20-22]. However, little information on the sorption of TBBPA and its analogue compounds by clay minerals modified with CTMAB has been reported.

Given the above, two typical clays (montmorillonite and kaolinite) were utilized to prepare CTMAB-modified clays. The objective of this work is to compare the sorption characteristics of TBBPA, BPA, and 2,6-DBP onto CTMAB-modified clays, and demonstrate their potential for uptaking those compounds from aqueous solutions under different conditions.

\section{Material and Methods}

\section{Materials}

TBBPA (99\% purity, Mw 543.9g/mol, CAS number 7994-7), bisphenol-A (99.8\% purity, Mw $228.29 \mathrm{~g} / \mathrm{mol}$, CAS number 80-05-7) (BPA), and 2,6-DBP (97\% purity, Mw 251.90g/mol, CAS number 608-33-3) were purchased from Sigma Chemical Co., Ltd (USA). K10-montmorillonite (Na-montmorillonite, one kind of acidic montmorillonite) and Kaolinite were obtained from Aladdin Chemistry Co., Ltd (Shanghai, China). Cetyltrimethyl ammonium bromide (CTMAB) was obtained from Bio Science \& Technology Co., Ltd (Shanghai, China). The selected physico-chemical properties of these chemicals are given

Table 1. Selected physico-chemical data for TBBPA, BPA, 2,6-DBP, and CTMAB.

\begin{tabular}{|c|c|c|c|c|c|}
\hline Abbreviation & $\mathrm{MW}(\mathrm{g} / \mathrm{mol})$ & $\mathrm{Sw}(\mathrm{umol} / \mathrm{L})$ & $\mathrm{pK}_{\mathrm{a}}$ & $\begin{array}{c}\log \\
\left(\mathrm{K}_{\mathrm{ow}}\right.\end{array}$ \\
\hline TBBPA & 543.9 & 8.5 & $7.50-8.50$ & 4.50 \\
\hline 2,6-DBP & 228.3 & 525.6 & $10.0-11.0$ & 3.32 \\
\hline CTMAB & 251.9 & 472.4 & 6.67 & 3.36 \\
\hline
\end{tabular}

MW: molecule weight; Sw: solution in the water. 
in Table 1 [23-24]. Cation-exchange capacity (CEC) was estimated using an ethylenediamine complex of copper method [21]. The cation-exchange capacities (CECs) were 44.3 and 3.9 mequiv/100g, respectively. Methanol was of HPLC grade and purchased from Fisher Co., Ltd (ShangHai, China). Ultrapure water was obtained directly from a Nanopure UV deionization system, Barnstead/ Thermolyne Co., Ltd (Dubuque, IA, USA). All other chemicals were of analytical grade unless stated otherwise.

\section{Preparation of CTMAB-Modified Clays}

The CTMAB-modified montmorillonite (CMt) and CTMAB-modified kaolinite (CKa) were synthesized according to procedures provided elsewhere [21]. $5.0 \mathrm{~g}$ of raw clays was dispensed in $0.1 \mathrm{~L}$ distilled water. A certain amount of CTMAB equivalent to the various percentages of the cation-exchange capacities (CECs) $(30 \%, 50 \%$, $70 \%$, and $100 \%$ ) was dissolved in $0.2 \mathrm{~L}$ of distilled water and then slowly added to the clays dispersion. The suspension was stirred for $24 \mathrm{~h}$ at $25^{\circ} \mathrm{C}$ and filtered by vacuum filtration. The treated clays were washed several times with distilled water until the $\mathrm{Br}$ was not detected by $\mathrm{AgSO}_{4}$ solution. The obtained clays were dried at $65^{\circ} \mathrm{C}$ and activated for $1 \mathrm{~h}$ at $105^{\circ} \mathrm{C}$. The $0.3 \mathrm{CEC}, 0.5 \mathrm{CEC}$, 0.7CEC, and 1.0CEC mean that CTMAB-modified clays were at $30 \%, 50 \%, 70 \%$, and $100 \%$ of cation-exchange capacities of the clays, respectively.

\section{Characterization of Sorbents}

X-ray powder diffraction (XRD) data was collected with a Rigaku D/MAX2200 diffraction meter operated at $30 \mathrm{kV}$ and $30 \mathrm{~mA}$ with $\mathrm{Cu} \mathrm{K} \alpha$ radiation. The XRD patterns were recorded from $4^{\circ}$ to $60^{\circ}$ of $2 \theta$ with a scan speed of $4 \%$ min. Fourier transform infrared (FTIR) spectra were recorded with a $\mathrm{KBr}$ pellet on a Thermo Nicolet-IS10 FTIR spectrometer in the spectral range $4,000-400 \mathrm{~cm}^{-1}$. BET analysis was performed on a Micromeritics ASAP 2020 surface area analyzer (Quantachrome, United states). Specific surface area was calculated on the basis of the BET equation. Scanning electron microscopy (SEM) micrographs were obtained using a Gemini Leo 1550 instrument. Before the scanning process, all samples were dried and coated with gold to enhance electron conductivity.

\section{Sorption Experiment}

A known mass of organoclays $(20 \mathrm{mg}$ ) was added to each of several $20 \mathrm{ml}$ glass vials. Each vial was then filled to capacity with water containing $0.1 \mathrm{~mol} \mathrm{~L}^{-1} \mathrm{CaCl}_{2}$ and $100 \mathrm{mg} \mathrm{L}^{-1} \mathrm{NaN}_{3}$ to have a constant electrolyte concentration and inhibit microbial activity. Solute was then added in a methanol carrier (concentrations of TBBPA, BPA and 2,6-DBP were from $0.4 \mathrm{mmol} \mathrm{L}^{-1}$ to $4.0 \mathrm{mmol} \mathrm{L}^{-1}$ ) while keeping methanol concentrations at less than $0.5 \%(\mathrm{v} / \mathrm{v})$ to avoid co-solvent effects. Following solute addition, the vials were sealed with a PTFE-cap and shaken at
$150 \mathrm{rpm}$ for equilibrium and centrifuged at 3,500 rpm for $15 \mathrm{~min}$. An aliquot of supernatant was removed for analysis. A similar procedure was adopted for the thermodynamic experiment, except that the temperature was varied for each isotherm.

The kinetics studies were first conducted in a $20 \mathrm{ml}$ vial by shaking $20 \mathrm{mg}$ of CTMAB-modified clays and $20 \mathrm{ml}$ solution containing pollutants $\left(2.0 \mathrm{umol} \mathrm{\textrm {L } ^ { - 1 }}\right)$ at $150 \mathrm{rpm}$. The sample was withdrawn at suitable time intervals. The concentration of TBBPA, BPA or 2,6-DBP was calculated by subtracting the final solution concentration as follows:

$$
q_{s}=\frac{\left(c_{0}-c_{t}\right) v}{\mathrm{~m}}
$$

... where $\mathrm{q}_{\mathrm{s}}(\mathrm{mg} / \mathrm{g})$ is the amount of contaminants adsorbed on adsorbents, $c_{0}(\mathrm{mg} / \mathrm{L})$ and $\mathrm{c}_{\mathrm{t}}(\mathrm{mg} / \mathrm{L})$ are the initial and final solution concentrations of contaminants, $\mathrm{v}(\mathrm{ml})$ is the volume of solution, and $\mathrm{m}(\mathrm{g})$ is the mass of dry adsorbent used.

The sorption recycle experiment was investigated. The initial concentration of TBBPA was $2.0 \mathrm{umol} / \mathrm{L}$. The adsorbent was 0.7CEC-montmorillonite.

\section{Analysis Methods}

The content of each sample was determined by highperformance liquid chromatography (HPLC) (Shimadzu LC-20AT, Kyoto, Japan) equipped with a photodiode array detector (SPD-M2OAV) and a VP-ODS column $(150 \times 4.6 \mathrm{~mm}, 5 \mu \mathrm{m})$ under the following conditions: $80 \%$ methanol (20\% water with a wavelength of $209 \mathrm{~nm}$ for analysis of TBBPA), 70\% methanol (30\% water with a wavelength of $280 \mathrm{~nm}$ for analysis of BPA), and $75 \%$ methanol $(25 \%$ water with a wavelength of $279 \mathrm{~nm}$ for analysis of 2,6-DBP). The injection volume was $20 \mu \mathrm{l}$ for all solutions. The column was operated at $35^{\circ} \mathrm{C}$. All of the solution was injected at a flow of $0.8 \mathrm{ml} \mathrm{min}^{-1}$.

\section{Results and Discussion}

\section{Characterization of CTMAB-Modified Clays}

$$
\text { FTIR analysis. }
$$

The FTIR spectrums of clays, CTMAB clays, and CTMAB clays loaded with TBBPA are shown in Fig. 1. Compared with the raw clays, new peaks (2917-2926 $\mathrm{cm}^{-1}$ and $2852-2857 \mathrm{~cm}^{-1}$ ) were observed in organoclays. The new peaks corresponded to the $\mathrm{CH}_{2}$ and the $\mathrm{CH}_{3}$ symmetric stretching mode, respectively. The splitting of the methylene scissoring mode between $1,480 \mathrm{~cm}^{-1}$ and $1,500 \mathrm{~cm}^{-1}$ in FTIR was considered to be diagnostic of the packing density increase in the intercalated surfactants within the clay gallery, which indicated that CTMAB was successfully intercalated into the montmorillonite and kaolinite. The spectrum of CTMAB clays loaded 

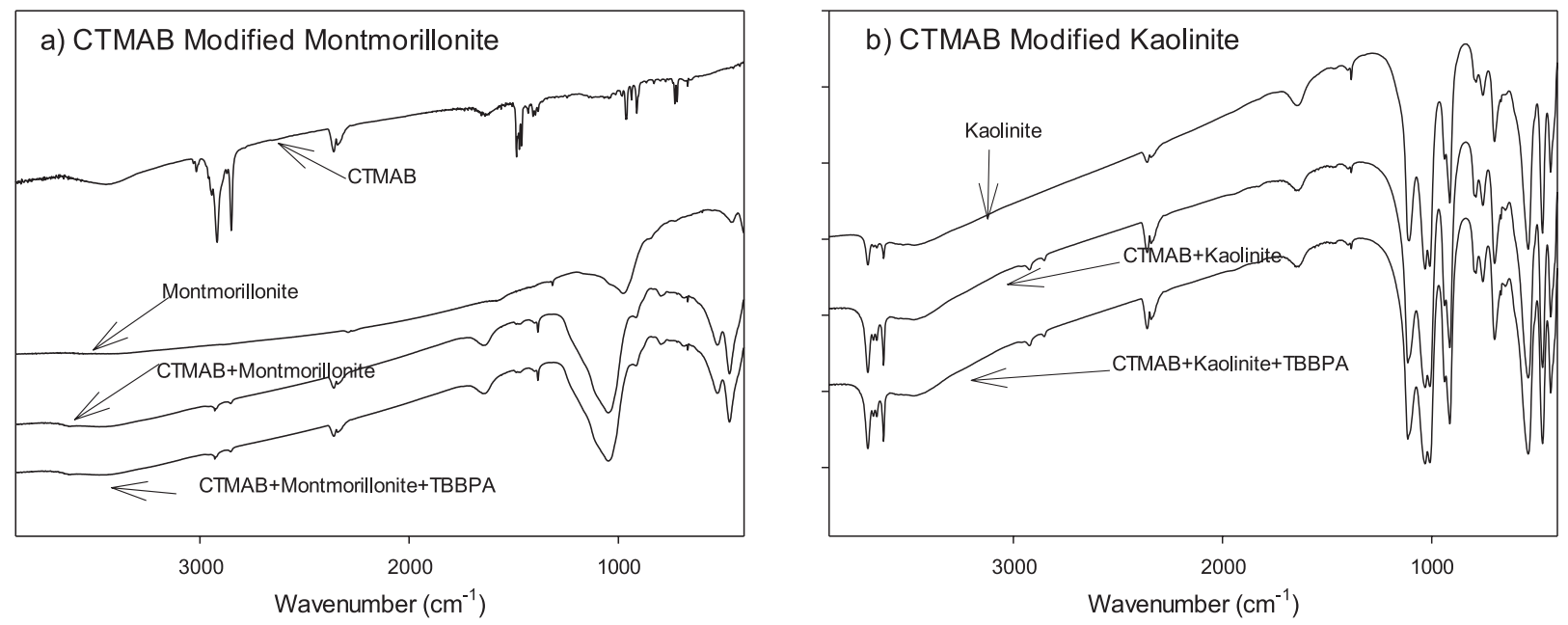

Fig. 1. FTIR spectra of clays and CTMAB clays a) Mt, CTMAB-Mt, and CTMAB-Mt-TBBPA; b) Ka, CTMAB-Ka, and CTMAB-KaTBBPA.

with TBBPA was similar to that of CTMAB clays. The unchanged spectrum indicated that the hydrophobicity interaction rather than chemical bonding probably played an important role in the sorption process.

\section{SEM Analysis}

The surface modification of clays with cationic surfactants involves both cation exchange process and the bonding of the hydrophobic moiety in the clay layers. SEM was utilized to investigate the modification mechanism for montmorillonite and kaolinite, and the result is presented in Fig. 2. The SEM micrograph of montmorillonite indicates that montmorillonite exhibited a disorder and heterogeneous surface structure. Kaolin samples show structural differences in term of crystallinity and the order-disorder structure (well-ordered and homogeneous surfaces structure). After being loaded with CTMAB, the surface topography of those materials did not undergo changes, suggesting that the cation exchange process and the bonding of hydrophobic moiety did not decompose the structure of polymeric sheets of clays.

\section{XRD and BET Analysis}

Basal spacing values $\left(\mathrm{d}_{001}\right)$ of the samples were calculated from 20 values of the peaks in the XRD patterns. As shown in Table $2, \mathrm{~d}_{001}$ values kept constant after intercalation of surfactant, which indicated that the surfactant did not increase the original clays interlayer distance any further. The $\mathrm{N}_{2}$ sorption isotherms were utilized to calculate the BET surface area. The surface area for montmorillonite was significantly decreased after CTAMB loading. Runliang Zhu et al. (2008) reported a similar phenomenon that the BET surface areas and total pore volumes were reversely related to the CTMABloading amount [25]. For the organoclays with relatively high surfactant loading amounts, their surface areas are extremely small due to the filling of pores by surfactants.

\section{Sorption Kinetics}

The effect of contact time on three compounds absorbed by organoclays is shown in Fig. 3. The adsorbed amounts of three selected compounds increased as time increased. All the curves had similar characteristics, showing an important and fast sorption (between $\mathrm{t}=0$ and $1 \mathrm{~h}$ ) and a slower sorption until equilibrium is accomplished. The fast sorption was usually attributed to the instantaneous monolayer sorption of the solutes at the surface, while the slow sorption could be related to desorption happening and intercalation into some interlayer region of the modified clays [26-27]. The maximum sorption of three contaminants onto organoclays was observed at $5 \mathrm{~h}$, which was fixed as the equilibrium contact time.

In order to investigate the sorption process of contaminants on the adsorbents, three common kinetic models (including the pseudo first-order, pseudo secondorder, and intra-particle diffusion models) were used to test the experimental data. The equations were as follow:

$$
\log \left(q_{e}-q_{t}\right)=\log \left(q_{e}\right)-\frac{\mathrm{k}_{1} \mathrm{t}}{2.303}
$$

$$
\begin{aligned}
& \frac{t}{q_{t}}=\frac{1}{k_{2} q_{e}{ }^{2}}+\frac{t}{q_{e}} \\
& q_{t}=k_{p} t^{1 / 2}+c
\end{aligned}
$$

... where $\mathrm{q}_{\mathrm{e}}$ and $\mathrm{q}_{\mathrm{t}}$ are the amount adsorbed at equilibrium and time $\mathrm{t}(\mathrm{h}), \mathrm{k}_{1}$ and $\mathrm{k}_{2}$ are the rate constants of pseudo first-order sorption and pseudo second-order sorption, $\mathrm{k}_{\mathrm{p}}$ is the rate constant of intra-particle diffusion (determined from slope of the lines in Fig. 4), and c is the intercept. The results of solutes sorption onto organoclays are shown in Table 3. It can be seen that the experimental $\mathrm{q}_{\mathrm{e}}$ values showed good agreement with the calculated ones for 

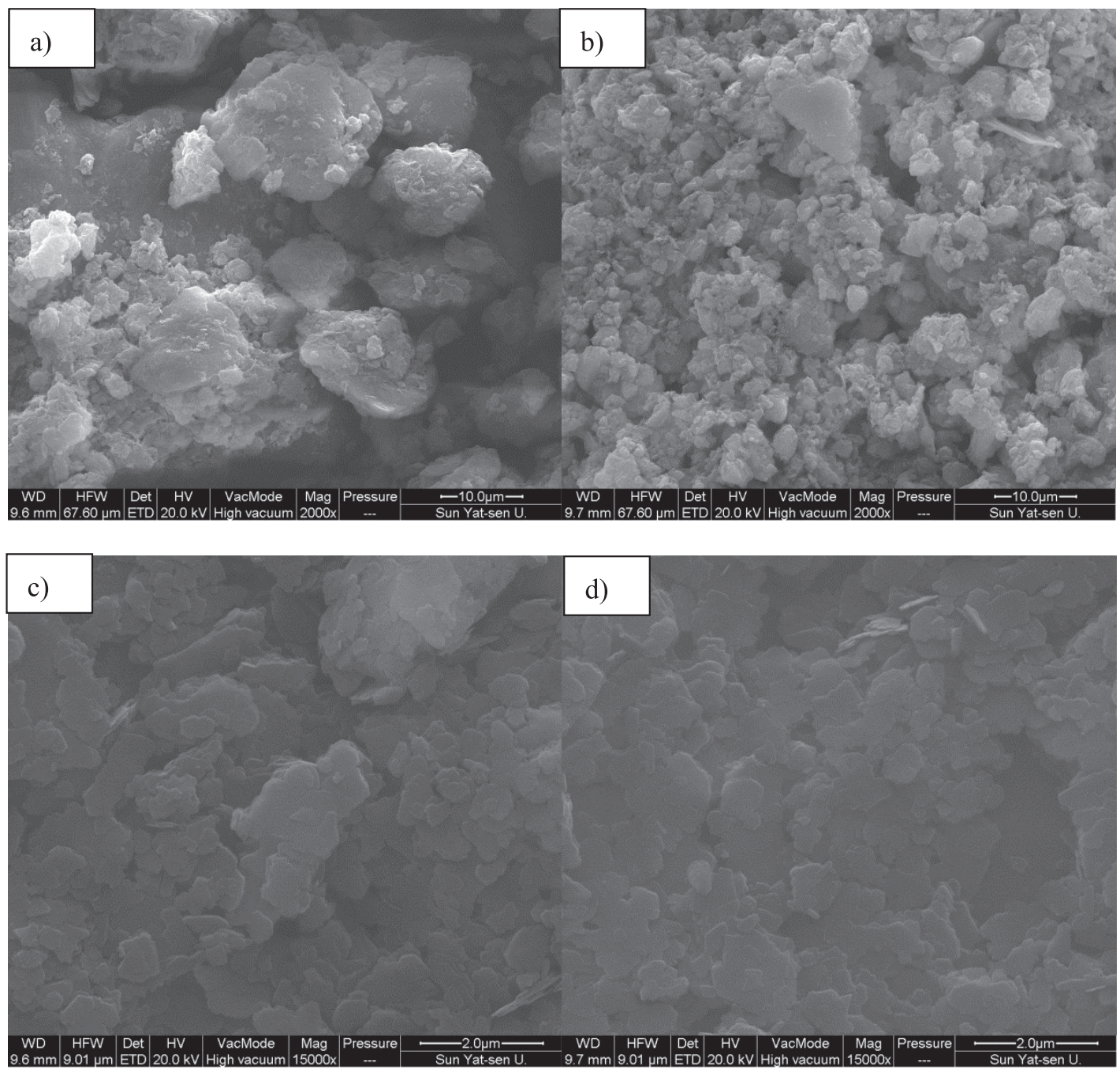

Fig. 2. Scan electron micrograph of raw and modified montmorillonite and kaolinite: a) raw montmorillonite, b) modified montmorillonite, c) raw kaolinite, and d) modified kaolinite.

pseudo second-order model. Meanwhile, the correlation coefficients $\left(\mathrm{R}^{2}\right)$ for the pseudo first-order kinetic model were between 0.155 and 0.775 , and correlation coefficients $\left(\mathrm{R}^{2}\right)$ for the pseudo second-order kinetic model were between 0.981 and 0.999 . It was probable that this sorption system was not a pseudo first-order reaction, and it fitted the pseudo second-order kinetic model.

For the intra-particle diffusion model the value of $\mathrm{c}$ was related to the thickness of the boundary layer. The larger the intercept, the greater the boundary layer effect
[28]. According to this model, if the plot of uptake (qt) versus the square root of time $\left(\mathrm{t}^{1 / 2}\right)$ was linear and passes through the origin, then intra-particle diffusion was the only rate-controlling step [22]. The plots of $\mathrm{q}_{\mathrm{t}}$ versus $\mathrm{t}^{1 / 2}$ in Fig. 4 are linear and did not pass through the origin, which suggested that the intra-particle diffusion into the interlayer of the organoclays was not the only rat-limiting step for removal of those compounds, but other processes [21].

Table 2. Characteristics of clays and CMTAB clays.

\begin{tabular}{|c|c|c|c|c|c|}
\hline Sample & $\begin{array}{c}\text { Cation exchange } \\
\text { capacity (CEC) }\end{array}$ & $\begin{array}{c}\text { BET surface area } \\
\left(\mathrm{m}^{2} / \mathrm{g}\right)\end{array}$ & $\begin{array}{c}\text { Basal spacing } \\
\left(\mathrm{d}_{001} \mathrm{~nm}\right)\end{array}$ & $\begin{array}{c}\text { Organic carbon content } \\
(\%)\end{array}$ & $\mathrm{pH}$ \\
\hline $\mathrm{Mt}$ & - & 252.38 & 1.03 & 0.23 & 4.1 \\
\hline $\mathrm{CMTAB}-\mathrm{Mt}$ & $70 \%$ & 128.33 & 1.01 & 11.66 & 6.8 \\
\hline $\mathrm{Ka}$ & - & 20.15 & 0.69 & 0.12 & 7.1 \\
\hline CMTAB-Ka & $70 \%$ & 19.73 & 0.72 & 1.25 & 6.9 \\
\hline
\end{tabular}



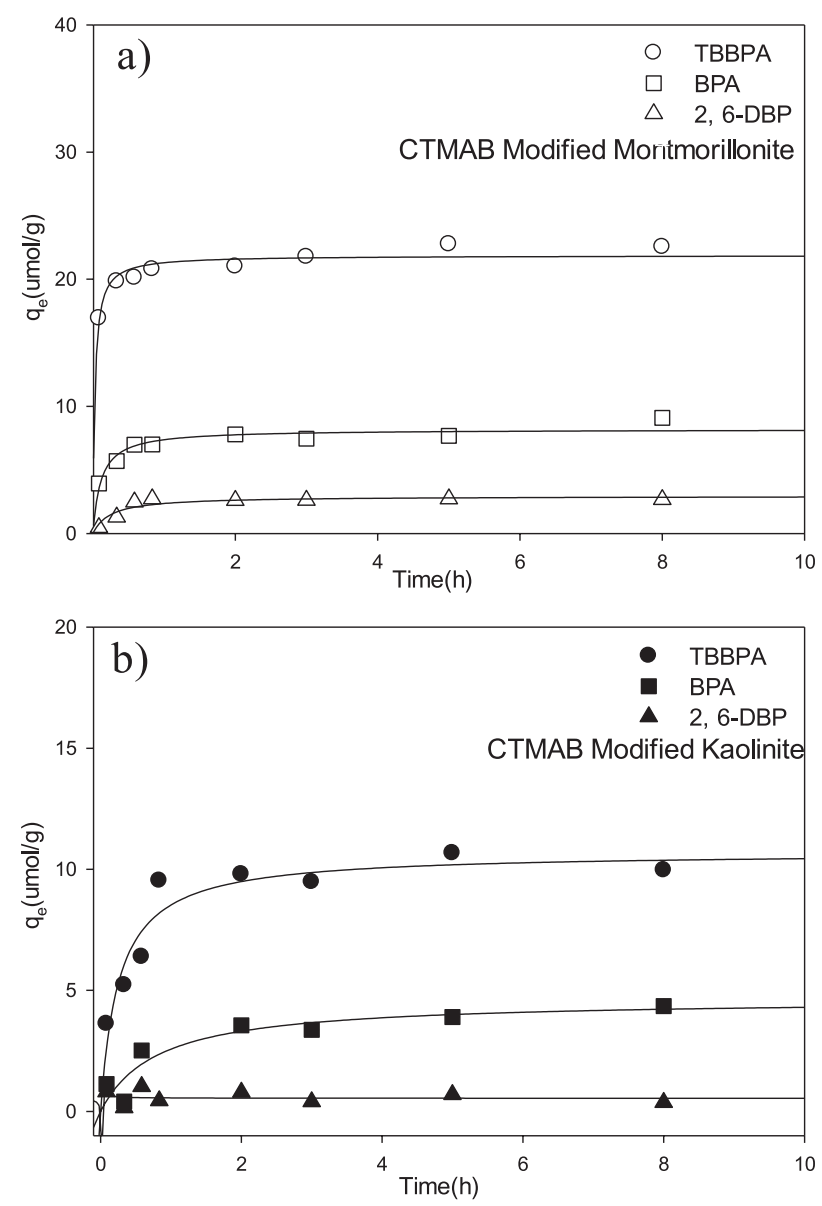

Fig. 3. Effects of contact time for three solutes adsorbed by CTMAB-modified clays: a) 0.7 CEC-CTMAB-Mt, b) 0.7 CECCTMAB-Ka (the initial concentrations of TBBPA, BPA, and 2,6-DBP were 2.0umol. $\mathrm{L}^{-1} ; \mathrm{pH}=6.5$ ).

\section{Sorption Isotherms}

The sorption isotherms of TBBPA, BPA, or 2,6-DBP by clays with various CTMAB loading was shown in Fig. 5. The data obtained from the isotherm equilibrium experiment were described by the Freundlich model:

$$
q_{e}=k_{F} c_{e}^{n}
$$

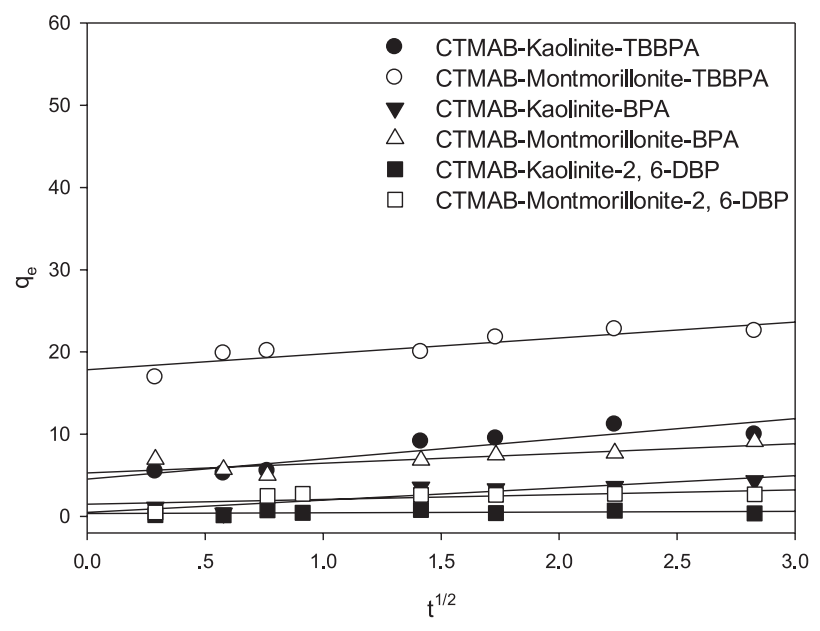

Fig. 4. Plots for intra-particle diffusion model for three solutes adsorbed by organoclays.

...where $\mathrm{q}_{\mathrm{e}}$ is the amount of the solutes adsorbed by adsorbents, $c_{e}$ is the concentration of the solutes in the aqueous phase, $\mathrm{k}_{\mathrm{F}}$ is the sorption capacity, and $\mathrm{n}$ represents the sorption intensity that could be used to calculate the magnitude of the sorption force of adsorbents to the solutes. The distribution coefficient $\left(\mathrm{k}_{\mathrm{d}}\right)$ was also calculated by $\mathrm{k}_{\mathrm{d}}$ $=\mathrm{q}_{\mathrm{e}} / \mathrm{c}_{\mathrm{e}}$, with the initial concentration of 0.5 umol. $\mathrm{L}^{-1}$ for three solutes. The organic carbon-normalized sorption coefficient $\left(\mathrm{k}_{\mathrm{oc}}\right)$ was calculated by $\mathrm{k}_{\mathrm{oc}}=\mathrm{k}_{\mathrm{d}} / f_{\mathrm{oc}}$, where $f_{\mathrm{oc}}$ is the mass fraction of carbon in the sorbents. The parameters are listed in the Table 4.

Clays modified with alkylammonium ions absorbed hydrocarbons through partitioning to give linear sorption isotherms, whereas the sorption of organic molecules having polar groups exemplified by phenolic compounds provided non-linear isotherms due to the contribution of specific sorption [20]. In this study, non-linear behaviors were observed for TBBPA, BPA, and 2,6DBP adsorbed by clays with low CTMAB loading ( 0.3 CEC). As CTMAB loading increased, the $n$ values for three compounds increased and approached 1, suggesting that partition behavior gradually played an important role in the sorption process. This also indicated that the sorption mechanism depended on the dose of surfactant. It was an obvious observation of the adsorption isotherms

Table 3. Parameters obtained from kinetic models.

\begin{tabular}{|c|c|c|c|c|c|c|c|c|c|c|c|}
\hline \multirow{2}{*}{ Sorbent } & \multirow{2}{*}{ Solutes } & \multirow[b]{2}{*}{$\mathrm{q}_{\mathrm{e}^{\prime} \exp }$} & \multicolumn{3}{|c|}{ Pseudo first-order } & \multicolumn{3}{|c|}{ Pseudo second-order } & \multicolumn{3}{|c|}{ Intra-particle diffusion } \\
\hline & & & $\mathrm{k}_{1}$ & $\mathrm{q}_{\mathrm{e}, \mathrm{cal}}$ & $\mathrm{R}^{2}$ & $\mathrm{~K}_{2}$ & $\mathrm{q}_{\mathrm{e}, \mathrm{cal}}$ & $\mathrm{R}^{2}$ & $\mathrm{k}_{\mathrm{p}}$ & $\mathrm{c}$ & $\mathrm{R}^{2}$ \\
\hline \multirow{3}{*}{$\begin{array}{c}\text { CTMAB } \\
-\mathrm{Mt}\end{array}$} & TBBPA & 21.383 & 0.47 & 3.923 & 0.667 & 0.448 & 22.781 & 0.999 & 1.412 & 18.911 & 0.821 \\
\hline & BPA & 8.902 & 1.06 & 10.503 & 0.714 & 0.273 & 9.042 & 0.986 & 1.647 & 4.333 & 0.930 \\
\hline & 2,6-DBP & 2.666 & 0.32 & 6.493 & 0.150 & 2.499 & 2.750 & 0.998 & 0.785 & 0.934 & 0.797 \\
\hline \multirow{3}{*}{$\begin{array}{c}\text { CMTAB } \\
-\mathrm{Ka}\end{array}$} & TBBPA & 11.023 & 0.61 & 4.676 & 0.772 & 0.333 & 10.638 & 0.991 & 2.522 & 4.389 & 0.782 \\
\hline & BPA & 5.632 & 0.47 & 2.679 & 0.775 & 0.103 & 5.302 & 0.992 & 1.928 & 0.514 & 0.801 \\
\hline & 2,6-DBP & 0.398 & 0.23 & 2.867 & 0.155 & 15.269 & 0.418 & 0.981 & 0.101 & 0.514 & 0.881 \\
\hline
\end{tabular}


Table 4. The parameters obtained from Freundlich model for TBBPA, BPA, and 2,6-DBP sorption to CTMAB-modified clays.

\begin{tabular}{|c|c|c|c|c|c|c|c|c|}
\hline Solutes & \multicolumn{2}{|c|}{ Adsorbents } & $\mathrm{k}_{\mathrm{F}}(\mathrm{L} / \mathrm{g})$ & $\mathrm{n}$ & $\mathrm{R}^{2}$ & $\mathrm{k}_{\mathrm{d}}{ }^{*}(\mathrm{~L} / \mathrm{g})$ & $f_{o c}(\%)$ & $\mathrm{k}_{\mathrm{oc}}^{*}(\mathrm{~L} / \mathrm{g})$ \\
\hline \multirow{8}{*}{ ТВBPA } & \multirow{4}{*}{$\begin{array}{c}\text { CTMAB- } \\
\text { Montmorillonite }\end{array}$} & 0.3CEC & 24.623 & 0.443 & 0.986 & 36.226 & 6.209 & 583.436 \\
\hline & & $0.5 \mathrm{CEC}$ & 291.175 & 0.925 & 0.997 & 306.712 & 8.982 & 3414.745 \\
\hline & & $0.7 \mathrm{CEC}$ & 742.241 & 1.052 & 0.995 & 715.964 & 11.657 & 6141.926 \\
\hline & & 1.0CEC & 1845.348 & 1.064 & 0.896 & 1765.275 & 13.354 & 13219.073 \\
\hline & \multirow{4}{*}{$\begin{array}{l}\text { CTMAB- } \\
\text { Kaolinite }\end{array}$} & $0.3 \mathrm{CEC}$ & 3.471 & 0.494 & 0.926 & 4.929 & 0.378 & 1304.019 \\
\hline & & $0.5 \mathrm{CEC}$ & 6.630 & 0.593 & 0.959 & 8.791 & 0.804 & 1093.394 \\
\hline & & $0.7 \mathrm{CEC}$ & 9.383 & 0.524 & 0.997 & 12.177 & 1.259 & 967.171 \\
\hline & & 1.0CEC & 17.051 & 0.665 & 0.996 & 21.508 & 4.017 & 535.418 \\
\hline \multirow{8}{*}{ BPA } & \multirow{4}{*}{$\begin{array}{c}\text { CTMAB- } \\
\text { Montmorillonite }\end{array}$} & $0.3 \mathrm{CEC}$ & 2.158 & 0.654 & 0.978 & 2.743 & 6.209 & 44.176 \\
\hline & & $0.5 \mathrm{CEC}$ & 2.779 & 0.916 & 0.996 & 2.946 & 8.982 & 32.795 \\
\hline & & $0.7 \mathrm{CEC}$ & 3.819 & 0.846 & 0.992 & 3.965 & 11.657 & 34.011 \\
\hline & & 1.0CEC & 5.340 & 0.971 & 0.982 & 5.448 & 13.354 & 40.800 \\
\hline & \multirow{4}{*}{$\begin{array}{l}\text { CTMAB- } \\
\text { Kaolinite }\end{array}$} & $0.3 \mathrm{CEC}$ & 0.470 & 0.920 & 0.977 & 0.382 & 0.378 & 100.994 \\
\hline & & $0.5 \mathrm{CEC}$ & 0.688 & 1.151 & 0.979 & 0.620 & 0.804 & 77.068 \\
\hline & & $0.7 \mathrm{CEC}$ & 1.009 & 0.996 & 0.986 & 1.012 & 1.259 & 80.365 \\
\hline & & 1.0CEC & 1.171 & 1.352 & 0.996 & 1.211 & 4.017 & 30.137 \\
\hline \multirow{8}{*}{ 2,6-DBP } & \multirow{4}{*}{$\begin{array}{c}\text { CTMAB- } \\
\text { Montmorillonite }\end{array}$} & $0.3 \mathrm{CEC}$ & 0.042 & 0.427 & 0.626 & 0.062 & 6.209 & 1.006 \\
\hline & & $0.5 \mathrm{CEC}$ & 0.146 & 1.101 & 0.961 & 0.136 & 8.982 & 1.516 \\
\hline & & $0.7 \mathrm{CEC}$ & 0.559 & 0.981 & 0.993 & 0.566 & 11.657 & 4.859 \\
\hline & & 1.0CEC & 1.239 & 0.789 & 0.998 & 1.248 & 13.354 & 9.349 \\
\hline & \multirow{4}{*}{$\begin{array}{l}\text { CTMAB- } \\
\text { Kaolinite }\end{array}$} & $0.3 \mathrm{CEC}$ & 0.024 & 0.885 & 0.694 & 0.026 & 0.378 & 6.876 \\
\hline & & $0.5 \mathrm{CEC}$ & 0.048 & 1.683 & 0.969 & 0.042 & 0.804 & 5.259 \\
\hline & & $0.7 \mathrm{CEC}$ & 0.100 & 1.470 & 0.996 & 0.072 & 1.259 & 5.734 \\
\hline & & 1.0CEC & 0.170 & 1.270 & 0.986 & 0.141 & 4.017 & 3.510 \\
\hline
\end{tabular}

$* \mathrm{k}_{\mathrm{d}}$ was calculated by $\mathrm{k}_{\mathrm{d}}=\mathrm{q}_{\mathrm{e}} / \mathrm{c}_{\mathrm{e}}$ with solute concentration of $0.5 \mathrm{umol} / \mathrm{L} ; \mathrm{k}_{\mathrm{oc}}$ was calculated by $\mathrm{k}_{\mathrm{oc}}=\mathrm{k}_{\mathrm{d}} / \mathrm{f}_{\mathrm{oc}}$

(Fig. 5) and the adsorption coefficients $\left(\mathrm{K}_{\mathrm{F}}\right)$ that the modified clays with high CTMAB loading (0.7CEC) were much more efficient adsorbents of TBBPA and its analogue compounds than the modified clays with low CTMAB loading (0.3 CEC). The increase in the sorption coefficients should be attributed to the increase of organic surfactants modification. The loaded surfactants created the organic solvent-like hydrophobic phase and the interaction can be described as a partition mechanism, resulting in a strong attraction of solutes with organic modified clays through van der Waals interaction.

\section{Influence of Molecule Properties on Sorption}

Previous studies have reported that the larger the octanol-water partition coefficient $\left(\log \mathrm{K}_{\mathrm{ow}}\right)$, the more likely a compound would be adsorbed into the organic phase composed of CTMAB alkyl groups exchanged into clays $[20,29]$. However, as shown in Tables 1 and 4 , the $\log \mathrm{K}_{\text {ow }}$ value in this study followed the order of $\mathrm{TBBPA}>2,6-\mathrm{DBP} \approx \mathrm{BPA}$, and the sorption coefficients were in the order of TBBPA $>$ BPA $>2,6-\mathrm{DBP}$. Apparently the sorption coefficients depend not only on $\log \mathrm{K}_{\text {ow }}$, but also on molecule properties such as molecule mass and size, the number of rings, and functional groups. Moreover, TBBPA consists of two hydroxyphenyl rings linked by a carbon bridge with bromine substitution at the 3, 3', 5, and 5 ' positions. TBBPA could occupy more clay surface, and the delocalized $\pi$-bond systems in TBBPA interact strongly with the cationic ammonium center and alkyl chains of CTMAB. This interaction can result in a reorientation of the alkyl substituent to a more orthogonal position and thus allow TBBPA interaction with the revealed mineral surfaces. A more orthogonal position of the alkyl chain expands the CTMAB-modified clay's interlamellar region, which makes more interlayer region accessible for TBBPA sorption and eventually increases 

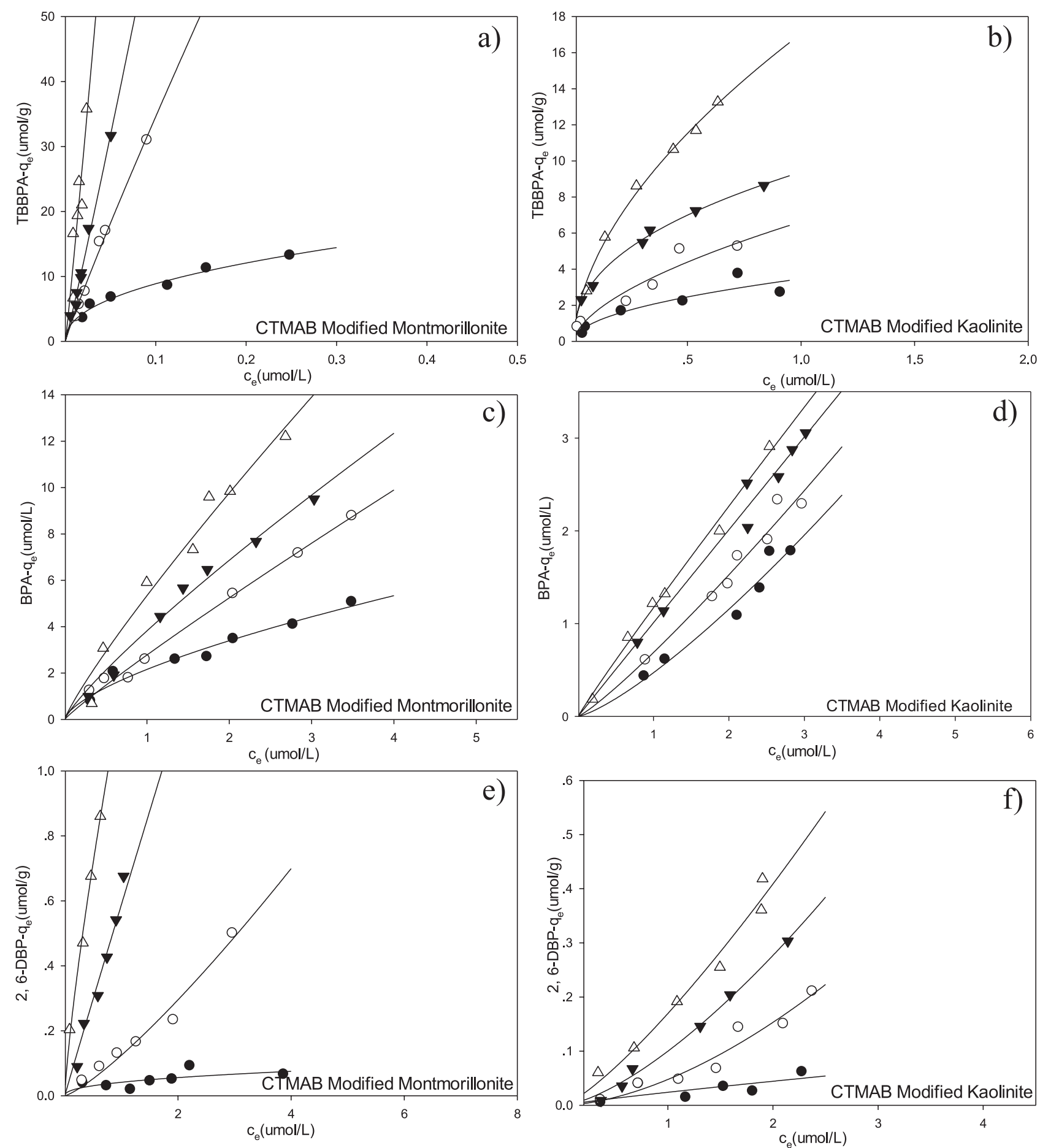

Fig. 5. Sorption isotherms of three compounds onto CTMAB clays $(\mathrm{pH}=6.5)$ : a) CMt-TBBPA, b) CKa-TBBPA, c) CMt-BPA, d) CKaBPA, e) CMt-2,6-DBP, and f) CKa-2,6-DBP.

Table 5. Thermodynamic parameters for sorption of TBBPA, BPA, and 2,6-DBP onto organoclays.

\begin{tabular}{|c|c|c|c|c|c|c|c|}
\hline \multicolumn{2}{|c|}{ Parameters } & TBBPA-M & BPA-M & $2,6-D B P-M$ & TBBPA-K & BPA-K & $2,6-D B P-K$ \\
\hline \multicolumn{2}{|c|}{$\Delta \mathrm{H}^{0}\left(\mathrm{~kJ}^{2} \cdot \mathrm{mol}^{-1}\right)$} & -26.424 & -12.869 & -8.539 & -7.226 & -5.929 & -5.4185 \\
\hline \multicolumn{2}{|c|}{$\Delta \mathrm{S}^{0}\left(\mathrm{~kJ}^{-1} \mathrm{~mol}^{-1} \cdot \mathrm{K}^{-1}\right)$} & 0.009 & 0.020 & 0.031 & 0.0646 & 0.014 & 0.006 \\
\hline $20^{\circ} \mathrm{C}$ & $\Delta \mathrm{G}^{0}\left(\mathrm{~kJ}^{\circ} \mathrm{mol}^{-1}\right)$ & -11.873 & -7.521 & -7.157 & -10.739 & -5.770 & -6.105 \\
\hline $30^{\circ} \mathrm{C}$ & $\Delta \mathrm{G}^{0}\left(\mathrm{~kJ}^{-1} \mathrm{~mol}^{-1}\right)$ & -11.343 & -7.513 & -7.017 & -10.638 & -6.056 & -7.572 \\
\hline $40^{\circ} \mathrm{C}$ & $\Delta \mathrm{G}^{0}\left(\mathrm{~kJ} \cdot \mathrm{mol}^{-1}\right)$ & -11.184 & -7.191 & -6.935 & -10.745 & -6.500 & -5.338 \\
\hline
\end{tabular}


the TBBPA sorption capacity. Thus, the sorption coefficient of TBBPA was much larger than that of BPA or 2,6-DBP.

Another mechanism suggested in this adsorption system may be donor-acceptor complex formation between the solute and adsorbent. Moreover, an electron acceptor (the positively charged head group of the surfactants) interacted with the oxygen atoms and bromine atoms in TBBPA, which acts as if an electron donator could also exist.

BPA consists of two hydroxyphenyl rings without bromine substitution. The molecule structure of BPA is similar to that of TBBPA. An electron acceptor (the positively charged head group of the surfactants) interacted with the oxygen atoms in BPA, which acts as if an electron donator could also exist. Meanwhile, BPA had a unique butterfly chemical structure and was wedged into the high energy site that resulted in the high sorption capacity [30]. The molecule size of BPA was larger than 2,6-DBP, and BPA could occupy more clay surface than 2,6-DBP. Therefore, the sorption coefficient of BPA over CTAMB-clays was much larger than that of 2,6-DBP. It could be speculated that the specific sorption that a nonplanar molecule wedge into the interlayer may be another factor for BPA sorption on organoclays.

2,6-DBP also had the delocalized $\pi$-bond systems and larger molecule mass than BPA. However, 2,6-DBP could not strongly interact with cationic ammonium center and alkyl chains of CTMAB, which resulted from the fact that 2,6-DBP had a small molecule size and consisted of only one hydroxyphenyl ring with bromine substitution. Thus, the sorption coefficients of 2,6-DBP were smaller than those of BPA. The low sorption affinity for 2,6-DBP also suggested that bromine atoms interacting with the cationic ammonium center of CTMAB was not the key factor for TBBPA and 2,6-DBP sorption onto CTMAB clays.

$$
\begin{gathered}
\text { Influence of CTMAB Coverage } \\
\text { on } \log k_{d} \text { and } \log k_{o c}
\end{gathered}
$$

As presented in Fig. 6 (b), $\log \mathrm{k}_{\mathrm{d}}$ of CTMAB-modified clays increased with CTMAB loading, which indicated that CTMAB amounts had a positive effect on sorption capacity. The existence of a positive relationship between amounts of CMTAB with their sorption capacity (log $\mathrm{k}_{\mathrm{d}}$ ) could explain that $\log \mathrm{k}_{\mathrm{d}}$ of CTMAB-Mt at each CTMAB coverage was higher than those of CTMAB-Ka (Fig. 6b), suggesting that the sorption capacity depended on the amount of CTMAB intercalated into clays. However, if $f_{\text {oc }}$ value was used, $\log \mathrm{k}_{\mathrm{oc}}$ (Fig. 6a) with $30 \%$ CEC surfactants coverage for CTMAB-Mt was lower than that for CTMAB-Ka. With the increase of CTMAB intercalated, $\log \mathrm{k}_{\mathrm{oc}}$ for CTAMB-Mt obviously increased. When surfactants coverage rose to $100 \%$ CEC, it became higher than that for CTMAB-Ka, which was consistent with the result of $\log \mathrm{k}_{\mathrm{d}}$. As previously noted, kaolinite had a non-swelling layer structure in which the surfactants adopted a vertical arrangement. Montmorillonite was swelling layer silicates and the surfactants always adopted the loose and disorder flat-lying arrangement in layer

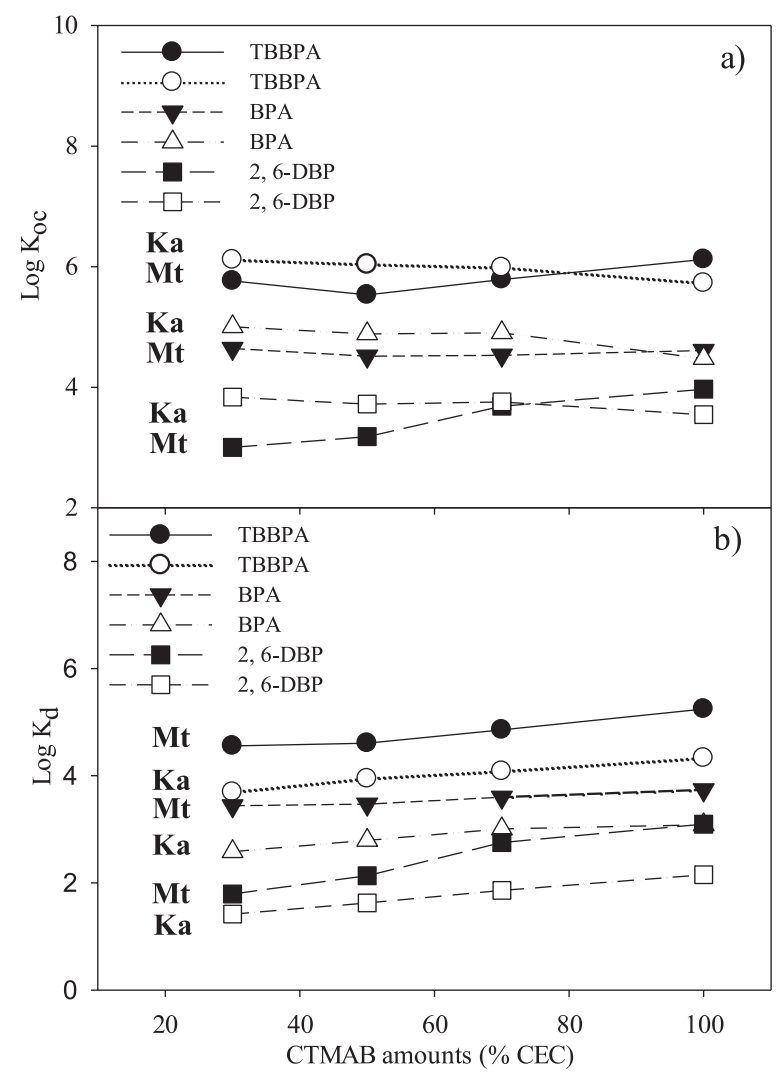

Fig. 6. TBBPA, BPA, and 2,6-DBP sorption distribution coefficients $\left(\log \mathrm{k}_{\mathrm{d}}(\mathrm{b})\right)$ and organic carbon-normalized sorption distribution coefficients $\left(\log \mathrm{k}_{\mathrm{oc}}\right.$ (a)) for $30 \%, 50 \%, 70 \%$, and $100 \%$ organoclays, respectively.

than in wet state. Kaolinite could have a more stabilized CTMAB sorption layer than montmorillonite. However, Runliang Zhu (2007) reported that packing density of the adsorbed CTMAB was proportional to the surfactant loading amount.

With the increase of CTMAB packing density, the adsorbed CTMAB would form a series of partition phases showing different affinities to the solutes [25]. Sufficient loading of CTMAB might form some bi-layers that resulted in a reversal of charge on the external surface of the clay, providing sites where anions can possibly be retained. Hence, $\log \mathrm{k}_{\mathrm{oc}}$ values of CTMAB-Mt with high CTAMB coverage were larger than that of CTAMB-Ka. A recent study had confirmed larger $\log \mathrm{k}_{\mathrm{oc}}$ for CBs sorption on CTMAB-kaolinite than CTMAB-bentonite [23]. However, in this work 100\% CEC-CTMAB-Mt (K10 montmorillonite) showed an advantage of removal of biphenols and bromophenols than 100\% CEC-CTAMB$\mathrm{Ka}$, which can be seen from larger $\log \mathrm{k}_{\text {oc }}$ for TBBPA and its degradation products adsorbed by CTMAB-Mt than CTMAB-Ka.

\section{Thermodynamic Studies}

The thermodynamic parameters such as entropy $\left(\Delta \mathrm{S}^{0}\right)$, enthalpy $\left(\Delta \mathrm{H}^{0}\right)$, and free energy change $\left(\Delta \mathrm{G}^{0}\right)$ for sorption process were calculated by the following methods [31-32]. 
The constant $\mathrm{k}_{0}$ can be defined as:

$$
k_{0}=\frac{\alpha_{s}}{\alpha_{e}}=\frac{c_{s}}{c_{e}}
$$

...where $\alpha_{\mathrm{s}}$ is the activity of solutes adsorbed onto organic clays and $\alpha_{\mathrm{e}}$ is the activity of solutes in solution at equilibrium. Since the concentration of solutes in solution approaches zero, the activity coefficient approached unity. The value of $\mathrm{k}_{0}$ was confirmed through plotting the $1 \mathrm{nk}_{0}$ versus $c_{s}$, and exploring the $c_{s}$ to zero. The straight line obtained was fitted using linear least-squares analysis methods. The vertical axis intercept was regarded as $\operatorname{lnk}_{0}$.

Free energy change $\left(\Delta \mathrm{G}^{0}\right)$, enthalpy $\left(\Delta \mathrm{H}^{0}\right)$, and entropy $\left(\Delta \mathrm{S}^{0}\right)$ were calculated as follows:

$$
\begin{gathered}
\ln k_{0}=\frac{\Delta S^{0}}{R}-\frac{\Delta \mathrm{H}^{0}}{\mathrm{RT}} \\
\Delta G^{0}=-R T \ln k_{0}
\end{gathered}
$$

...where $\mathrm{R}$ was the universal gas constant (8.314 $\mathrm{J} . \mathrm{mol}^{-1} \cdot \mathrm{K}^{-1}$ ) and $\mathrm{T}$ was the sorption temperature. The value of $\Delta \mathrm{S}^{0}$ was defined by the intercept of vertical axis. The values of $\Delta \mathrm{H}^{0}$ and $\Delta \mathrm{G}^{0}$ were confirmed by the slope of equation (7) and equation (8), and the results are presented in Table 5. The negative values of $\Delta \mathrm{G}^{0}$ and $\Delta \mathrm{H}^{0}$ indicate that the sorption of TBBPA, BPA, and 2,6-DBP onto organic clays was spontaneous. The $\Delta \mathrm{G}^{0}$ values for solutes sorption onto CTMAB-montmorillonite and CTMABkaolinite were in the range $6.935-11.873 \mathrm{~kJ}^{-\mathrm{mol}^{-1}}$ and $3.572-10.539 \mathrm{~kJ} \mathrm{~mol}^{-1}$, respectively. For physical sorption, the $\Delta \mathrm{G}^{0}$ values were in the range $0-20 \mathrm{~kJ} \cdot \mathrm{mol}^{-1}$. The free energy change values $\left(\Delta \mathrm{G}^{0}\right)$ in this study showed that TBBPA, BPA, or 2,6-DBP sorption onto organoclays could be considered as the physical sorption. The values of enthalpy were high enough to ensure the hydrophobic

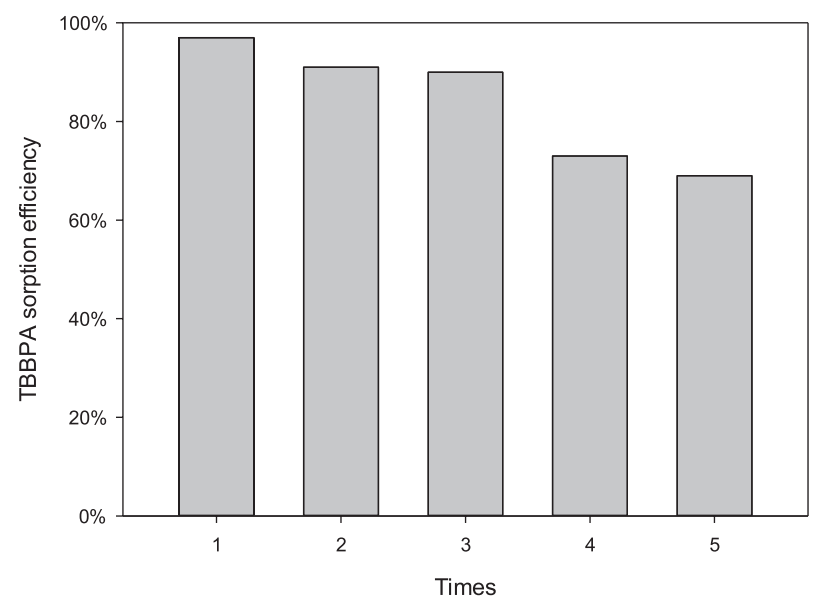

Fig. 7. The repeated experiments of sorption of TBBPA by 0.7 CEC-montmorillonite (run five times). interaction between adsorbates and adsorbents. The positive $\Delta S^{0}$ values stated that the randomness increased at the solid-solution interface during the TBBPA and its derivatives sorption onto organoclays.

\section{Recycle of Adsorbent}

The usability of the adsorbent was investigated by repeating TBBPA sorption experiments with recycled 0.7 CEC montmorillonite. The experiments were run five times. The results are shown in Fig. 7. The slight decrease of sorption efficiency observed in the fifth run indicates the excellent ability of organic modified clays.

\section{Conclusion}

The sorption of TBBPA, BPA, and 2,6-DBP fit well with the Freundlich model, which implied that the mechanism of TBBPA and its derivatives sorption onto CTMAB-modified clays is through the hydrophobic interaction between organic pollutants and surfactants. The sorption capacity coefficient $\mathrm{k}_{\mathrm{F}}$ was affected by the amounts of intercalated surfactants, while $\mathrm{k}_{\mathrm{oc}}$ was not. The results revealed that not only the clay type was the key to influencing sorption efficiency, but also that the proper amount of CTMAB could obtain the highest efficiency in the sorption of TBBPA, BPA, or 2,6-DBP onto organoclays. The sorption mechanism depended on the amount of CTMAB and molecule properties of solutes. The kinetic study illustrated that the sorption of TBBPA and its derivatives onto organic clays could be pseudo second-order. The thermodynamic parameters proved that the sorption was physical and spontaneous. The positive $\Delta \mathrm{S}^{0}$ values stated that the randomness increased at the solid-solution interface during the TBBPA and its derivatives sorption onto organoclays. A slight decrease of sorption efficiency was observed in the fifth run, indicating the excellent ability of organic modified clays.

\section{Acknowledgements}

This work was supported in part by a grant from the Environmental and Pollution Control Technology and the National Key Scientific and Technological Project "Water Pollution Control and Treatment" (Nos. 2012ZX07206002 and 2012ZX07206004). It was also supported in part by the Experiment Teaching Research Fund of Sun-Yansen University (No. YJ201318).

\section{Reference}

1. DECARLO V.J. Studies on brominated chemicals in the environment [J]. Annals of the New York Academy of Sciences, 320 (1), 678, 1979.

2. SUZUKI S., HASEGAWA A. Determination of hexabromocyclododecane diastereoisomers and tetrabromobisphenol A in water and sediment by liquid chromatography/ 
mass spectrometry $[\mathrm{J}]$. Analytical sciences: the international journal of the Japan Society for Analytical Chemistry, 22 (3), 469, 2006.

3. XIE Z., EBINGHAUS R., LOHMANN R., HEEMKEN O., CABA A., PÜTTMANN W. Trace determination of the flame retardant tetrabromobisphenol $\mathrm{A}$ in the atmosphere by gas chromatography - mass spectrometry $[\mathrm{J}]$. Analytica chimica acta, 584 (2), 333, 2007.

4. VOORDECKERS J.W., FENNELL D.E., KRISTI J., HAGGBLOM M.M. Anaerobic biotransformation of tetrabromobisphenol A, tetrachlorobisphenol A, and bisphenol A in estuarine sediments [J]. Environmental science \& technology, 36 (4), 696, 2002.

5. PENG X., ZHANG Z., ZHAO Z., JIA X. 16 S ribosomal DNA clone libraries to reveal bacterial diversity in anaerobic reactor-degraded tetrabromobisphenol A [J]. Bioresource technology, 112, 75, 2012.

6. GÁNDARA J.S., ABUÍN S.P., LOSADA P.P., LOZANO J.S. Determination of Bisphenols A and F in Noncured Epoxy Resins by RP-HPLC - Fluorescence Techniques[J]. Journal of chromatographic science, 31 (11), 450, 1993.

7. JAKAB E., UDDIN M.A., BHASKAR T., SAKATA Y. Thermal decomposition of flame-retarded high-impact polystyrene $[\mathrm{J}]$. Journal of analytical and applied pyrolysis, 68, 83, 2003.

8. TERAKADO O., OHHASHI R., HIRASAWA M. Thermal degradation study of tetrabromobisphenol-A under the presence metal oxide: Comparison of bromine fixation ability [J]. Journal of Analytical and Applied Pyrolysis, 91 (2), 303, 2011.

9. IKE M., CHEN M.Y., JIN C.S., FUJITA M. Acute toxicity, mutagenicity, and estrogenicity of biodegradation products ofbisphenol-A. Environ. Toxicol. 17, 457, 2002.

10. LEGLER J., BROUWER A. Are brominated flame retardants endocrine disruptors? [J]. Environment International, 29 (6), 879, 2003.

11. DECHERF S., SEUGNET I., FINI J.B., CLERGETFROIDEVAUX M.S., DEMENEIX B.A. Disruption of thyroid hormone-dependent hypothalamic set-points by environmental contaminants[J]. Molecular and cellular endocrinology, 323 (2), 172, 2010.

12. BIRNBAUM L.S., STASKAL D.F. Brominated flame retardants: cause for concern? [J]. Environmental health perspectives, 112 (1), 9, 2004.

13. HASSENKLÖVER T, BICKMEYER U. The marine secondary metabolites 2, 4-dibromophenol and 2, 4, 6-tribromophenol differentially modulate voltage dependent ion currents in neuroendocrine (PC12) cells [J]. Aquatic toxicology, 79 (4), 384, 2006.

14. OLSEN C.M., MEUSSEN-ELHOLM E.T.M., HOLME J.A., HONGSLO J.K. Brominated phenols: characterization of estrogen-like activity in the human breast cancer cell-line MCF-7 [J]. Toxicology letters, 129 (1), 55, 2002.

15. ZHANG J., HE S.L., REN H.X., WANG L.P., TIAN L.J. Removal of tetrabromobisphenol-A from wastewater by ozonation[J]. Procedia Earth and Planetary Science, 1 (1), $1263,2009$.

16. HORIKOSHI S., MIURA T., KAJITANI M., HORIKOSHI N., SERPONE N. Photodegradation of tetrahalobisphenol-A $(\mathrm{X}=\mathrm{Cl}, \mathrm{Br}$ ) flame retardants and delineation of factors affecting the process [J]. Applied Catalysis B: Environmental, 84 (3), 797, 2008.
17. Si L., SHAOGUI Y., XIAODONG W., CHENG S. Reductive degradation of tetrabromobisphenol A over iron silver bimetallic nanoparticles under ultrasound radiation [J]. Chemosphere, 79 (6), 672, 2010.

18. PENG X., JIA X. Optimization of parameters for anaerobic co-metabolic degradation of TBBPA [J]. Bioresource technology, 148, 386, 2013.

19. PENG X., ZHANG Z., LUO W., JIA X. Biodegradation of tetrabromobisphenol A by a novel Comamonas sp. strain, JXS-2-02, isolated from anaerobic sludge [J]. Bioresource technology, 128, 173, 2013.

20. WEI Q., NAKATO T. Competitive sorption of phenols on organically modified layered hexaniobate $\mathrm{K} 4 \mathrm{Nb} 6 \mathrm{O} 17$ [J]. Microporous and mesoporous materials, 96 (1), 84, 2006.

21. SHU Y., LI L., ZHANG Q., WU H. Equilibrium, kinetics and thermodynamic studies for sorption of chlorobenzenes on CTMAB modified bentonite and kaolinite [J]. Journal of hazardous materials, 173 (1), 47, 2010.

22. SELIEM M.K., KOMARNENI S., BYRNE T., CANNON F.S., SHAHIEN M.G., KHALIL A.A., ABD EI-GAID, I.M. Removal of nitrate by synthetic organosilicas and organoclay: Kinetic and isotherm studies [J]. Separation and Purification Technology, 110, 181, 2013.

23. SUN Z., YU Y., LI M., ZHENG F., YU H. Sorption behavior of tetrabromobisphenol A in two soils with different characteristics [J]. Journal of hazardous materials, 160 (2), 456, 2008.

24. U.S. National Library of Medicine: TOXICOLOGY DATA NETWORK (TOXNET DATA BASES), http://toxnet.nlm. nih.gov/, 2014.

25. ZHU R., ZHU L., XU L. Sorption characteristics of CTMAbentonite complexes as controlled by surfactant packing density [J]. Colloids and Surfaces A: Physicochemical and Engineering Aspects, 294 (1), 221, 2007.

26. SAWHNEY B.L., BROWN K. Sorption dynamics of organic compounds in soils and sediments [J]. 1989.

27. BRAIDA W.J., WHITE J.C., FERRANDINO F.J., PIGNATELLO J.J. Effect of solute concentration on sorption of polyaromatic hydrocarbons in soil: uptake rates [J]. Environmental science \& technology, 35 (13), 2765, 2001.

28. GERELI G., SEKI Y., MURAT KUŞOĞLU İ., YURDAKOÇ $\mathrm{K}$. Equilibrium and kinetics for the sorption of promethazine hydrochloride onto K10 montmorillonite [J]. Journal of colloid and interface science, 299 (1), 155, 2006.

29. MA J., ZHU L. Removal of phenols from water accompanied with synthesis of organobentonite in one-step process [J]. Chemosphere, 68 (10), 1883, 2007.

30. PAN B.O., BAOSHAN XING. Competitive and complementary sorption of bisphenol A and 17 $\alpha$-ethinyl estradiol on carbon nanomaterials. Journal of agricultural and food chemistry $\mathbf{5 8}$ (14), 8338, 2010.

31. PARK Y., SUN Z., AYOKO G.A., FROST R.L. Bisphenol A sorption by organo-montmorillonite: Implications for the removal of organic contaminants from water [J]. Chemosphere, 107, 249, 2014.

32. HAN WEI, LEI LUO, SHUZHEN ZHANG. Sorption of tetrabromobisphenol A on soils: contribution of soil components and influence of soil properties [J]. Colloids and Surfaces A: Physicochemical and Engineering Aspects, 428, 60, 2013. 